\title{
Fatigue Life Assessment for Power Cables in Floating Offshore Wind Turbines
}

\author{
Mohsen Sobhaniasl ${ }^{1}$, Francesco Petrini ${ }^{1, *} \mathbb{1}$, Madjid Karimirad ${ }^{2} \mathbb{C}$ and Franco Bontempi ${ }^{1}$ \\ 1 Department of Structural an Geotechnical Engineering, Sapienza University of Rome, 00184 Rome, Italy; \\ mohsen.sobhanias1@uniroma1.it (M.S.); franco.bontempi@uniroma1.it (F.B.) \\ 2 Civil Engineering, School of Natural and Built Environment, Queen's University Belfast (QUB), \\ Belfast BT7 1NN, UK; madjid.karimirad@qub.ac.uk \\ * Correspondence: francesco.petrini@uniroma1.it
}

Received: 6 May 2020; Accepted: 12 June 2020; Published: 15 June 2020

\begin{abstract}
In this paper, a procedure is proposed to determine the fatigue life of the electrical cable connected to a $5 \mathrm{MW}$ floating offshore wind turbine, supported by a spar-buoy at a water depth of 320 $\mathrm{m}$, by using a numerical approach that takes into account site-specific wave and wind characteristics. The effect of the intensity and the simultaneous actions of waves and wind are investigated and the outcomes for specific cable configurations are shown. Finally, the fatigue life of the cable is evaluated. All analyses have been carried out using the Ansys AQWA computational code, which is a commercial code for the numerical investigation of the dynamic response of floating and fixed marine structures under the combined action of wind, waves and current. Furthermore, this paper applies the FAST NREL numerical code for comparison with the ANSYS AQWA results.
\end{abstract}

Keywords: wind energy; floating offshore wind turbine; dynamic analysis; fatigue life assessment; flexible power cables

\section{Introduction}

Power cables are wideley used in power transmission lines and the electrification of floating oil and gas production infrastructures, where they have to withstand considerable cyclic loads induced by the combination of floating body dynamics with wind, waves and current effects [1,2].

One of the main design issues for power cables in marine applications is the fatigue strength; fatigue assessment studies have demonstrated that accurate analysis of the complex dynamic behavior induced by the offshore environment must be carried out for fatigue assessment purposes. Dai et al. (2020) [3] presented experimental and numerical studies on dynamic stress and curvature in steel tube umbilicals, and the results show that curvature, governs the fatigue problem, even when it is small. Yang et al. (2018) [4] presented a parametric study of the dynamic motions and mechanical characteristics of power cables for a wave energy conversion (WEC) system. The results show that the large curvature responses of the cable typically occur at high wave heights and near the wave period of resonance. Yang et al. (2017) [5], regarding the same WEC system, demonstrated that minor fouling can increase the fatigue life of the power cable.

A relatively new application area for marine power cable elements is floating offshore wind turbines (FOWTs) [6] and farms. In fact, wind energy has become one of the most important renewable energy sources in recent decades. Its development requires an increasing electric transmission capacity and better ways to preserve system reliability. Wind-generated power continues to grow rapidly throughout the world, and offshore wind farms are expected to account for a large portion of the total wind energy output and may even contribute significantly to the total electricity production in some countries [7]. The cost-effective operation of marine energy conversion systems needs the reliable 
design of marine power cables, which are currently the components for which design procedures mainly need further development, due to their limited fatigue strength. FOWTs in particular, together with their mooring systems and connected power cables, must withstand various environmental actions, such as correlated variability in the wind, current, and wave loads, which cause variable and uninterrupted dynamic motion and stress in the power cables that connect the single FOWTs with each other and/or with the land. The accumulation of variable stress results in cumulative damage to the fatigue [8], which, for this kind of system, is a weak point in the design panorama.This is something that, together with other design or operating issues, currently prevents the large-scale installation and diffusion of floating offshore wind farms as reliable systems for energy generation and as an evolution of the currently widely diffused fixed-foundation offshore wind farms. These weaknesses are particularly relevant for the electrical cables which connect the single turbines to one another in the farm [9], named "inter-array" or "umbilical" cables.

Therefore, the definition of advanced and reliable tools for the investigation of fatigue damage is necessary, and this topic is highly recognized by the research community [9] and the industry [10,11]. Design approaches in this area intend to ensure the required fatigue life for the structure or key parts of it [12], and they are devised toghether with appropriate inspection programs for monitoring fatigue damage initiations or progress.

This paper proposes a procedure for the fatigue life evaluation of a power cable which is attached to a single FOWT in a lazy wave geometrical configuration by considering (i) the correlated intensities of wind, ocean current and wave actions [13]; (ii) the different operating conditions of the turbine; (iii) the complete non-linear dynamics of the turbine-cable coupled system [14]; and (iv) the difference between fatigue actions in different locations along the cable. Several modeling issues are faced in order to increase confidence in the results obtained by the multiphysics modeling of the system. The wind field sampled by the rotor in operating conditions, the fluid-structure interaction between the wind and the FOWT due to the platform's large displacements, the joint bending and axial induced strain in the cable and the non-linearity involved in the problem (due to both large displacements and the appearance of plastic strains) are included in the analyses by making reliable assumptions and by calibrating the procedures employing sensitivity analyses. The objective of this paper is to provide a reliable procedure for assessing the fatigue failure of the power cables of FOWTs. The proposed procedure is applied to the umbilical cable attached to the spar-buoy supported 5 MW NREL wind turbine [15] in a water depth of $320 \mathrm{~m}$, considering site-specific wind, waves and current for a short-term sea state of the China Sea. The case study is modeled both in the FAST NREL code [15] and in the ANSYS AQWA Commercial code [16]. The obtained results offer supporting data for the a-priori identification of weaknesses and critical components for fatigue strength and for the evaluation of the desired level of reliability before deployment.

\section{Analysis Method for Fatigue Life Evaluation}

As is well known, the simplified relationship between the stress of amplitude $S i$ and the associated number of cycles $\mathrm{Ni}$ that leads to the fatigue failures of mechanical components under constant-amplitude oscillating loads can be represented for different intensities by the S-N $(\sigma-N)$ fatigue curve [17]. The S-N curve is a characteristic of the materials, of the shape of the component or of the design configuration of the structure. Under the indications provided in the Det Norske Veritas (DNV) design standards [18,19], the fatigue damage for different levels of stress oscillation magnitude can be calculated for the pertinent components of FOWTs by the Palmgren-Miner assumption, using Equation (1) [17]:

$$
D m=\Sigma \frac{n i}{N i_{c y c l e s}}
$$

where $D m$ is the accumulated fatigue damage due to all considered stress oscillation magnitudes, $n i$ is the number of the stress oscillations with magnitude $S i$ and $N i_{\text {cycles }}$ is the number of cycles of stress oscillation with magnitude $S i$ which lead to fatigue failure. 
The electrical cables that connect the FOWTs in floating offshore wind farms are of the umbilical typology, providing a service-support from the main station to the single FOWTs. Such umbilical cables are of the optical powered submarine type and are provided to supply electrical power or to send operating control inputs and data to underwater elements in offshore oil and gas infrastructures [20]. Umbilical cables are implemented in floating offshore wind farms and connected to each FOWT for the same purpose; therefore, their integrity and service ability are crucial for the correct coordination and operation of the FOWTs within the farm. The stress conditions in such non-homogeneous cross-sections of the umbilical cables is quite complex, with non-linear local stress due to contact and friction between the components of the tube, and the model and aleatory uncertainty due to this complexity is critical for the reliability of any fatigue analysis. For the sake of simplicity, and in line with state of the art literature on the topic [9], the cable will be modeled in this paper with a homogeneous-material equivalent to the cross-section.

As an alternative to the $\sigma-N$ plane, fatigue curves may also be represented by the total strain $(\varepsilon)$ versus the number of cycles $(N)$, as detailed below. Equation (1) is useful for both the stress versus number of cycles curve and the strain versus number of cycles curve $(\varepsilon-N)$. The evaluation of the total strain time history in a critical fatigue-prone location of the cable, and corresponding to a specific sea state, is conducted by a non-linear numerical analysis of the coupled FOWT-electrical cable system, and $\varepsilon$ accounts for both elastic $\left(\varepsilon_{e}\right)$ and plastic strain $\left(\varepsilon_{p}\right)$. This may then be expressed as follows [21]:

$$
\varepsilon(t)=\varepsilon_{e}(t)+\varepsilon_{p}(t)=\frac{\sigma_{e l}(t)}{E}+\varepsilon_{p}(t)
$$

where $E$ is the Young's elastic modulus assigned to the equivalent homogenous material modeling the cable, and $\sigma_{e l}$ is the elastic tension stress of the electrical cable, evaluated step-by-step as the maximum cross-section tensile stiffness in the homogeneous material cross-section by considering both the axial and bending contributions:

$$
\sigma_{e l}(t)=\frac{N(t)}{A}+\chi(t) \cdot E \cdot \frac{D}{2}
$$

in which, by referring to the circular cross-section of the cable, $N$ is the axial force, $A$ is the area, $\chi$ is the bending curvature and $D$ is the diameter.

The plastic strain contribution $\varepsilon_{p}$ enters the game only when the total stress, as evaluated by Equation (3), is larger than the yielding stress $\sigma_{y}$ of the cable, which can be evaluated from the strain-stress constitutive law assumed for the equivalent homogeneous material used for modeling the cable (see Figure 1), as detailed in Equation (4)

$$
\varepsilon_{p}(t)=\frac{\sigma_{y}}{E}+\frac{\sigma_{y}-\sigma_{e l}(t)}{E^{\prime}}
$$

where $E^{\prime}$ is the material plastic modulus.

The non-linear stress-strain behavior and relaxation characteristics mean that the impact of plastic strains plays a non-negligible role in the electrical cable's fatigue analysis. Inside the umbilical cable, the conductors, which are commonly made of pure electrolytic tough pitch (ETP) copper, are vulnerable to fatigue accumulation and mechanical failure, as highlighted by Karlsen and co-authors (2009) [11], who state that "the material has excellent conductivity but poor mechanical properties, which include stress-relaxation (creeping) and non-linear stress-strain behaviour, and they suggests using $\varepsilon-N$ curves (referring to strain) instead of traditional $\sigma-N$ curves".

The Monograph 177 [22] from the National Institute of Standards and Technology (NIST) summarizes the results of a total of 126 plastic strain-controlled tests and 150 stress-controlled tests that were performed on a large set of coppers made by annealed material and cold-worked material. The stress-controlled test data may be converted to elastic strain values according to Equation (2) with $\varepsilon_{p}=0$. 


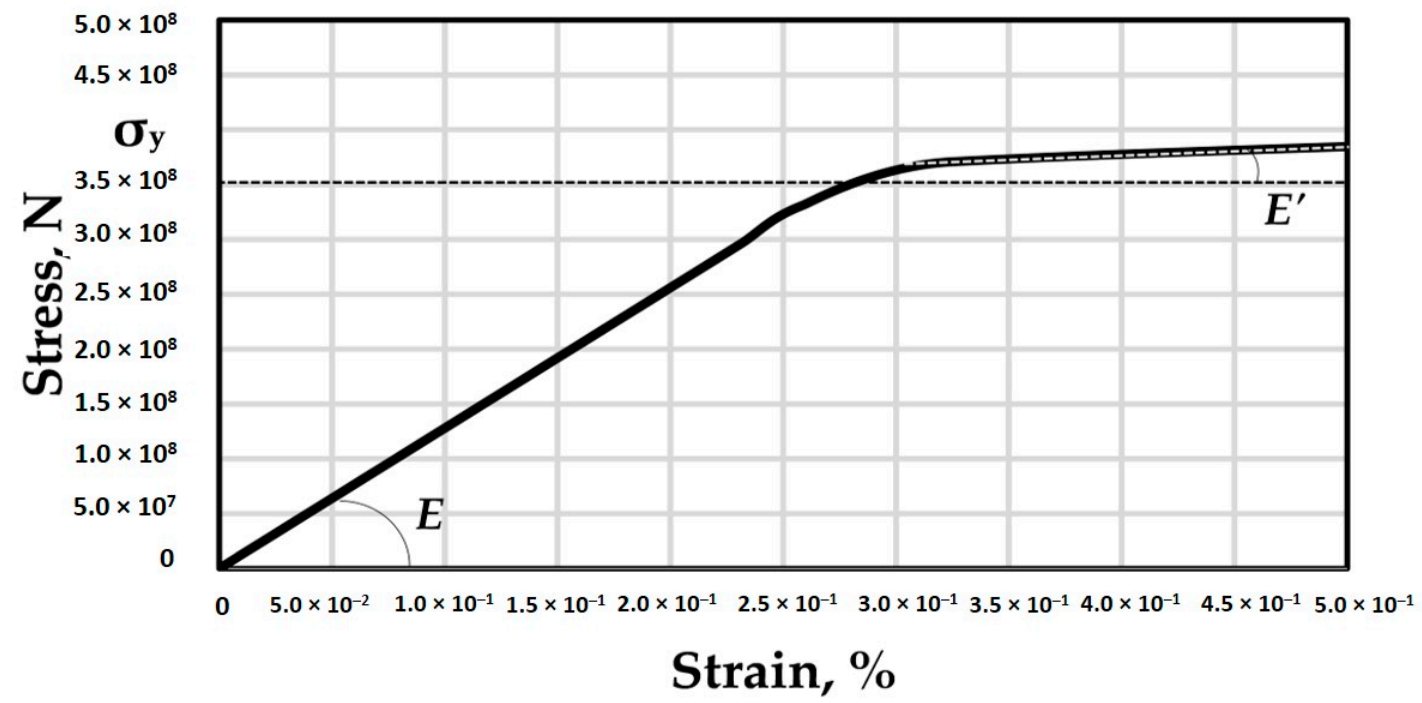

Figure 1. Stress-strain constitutive relationship of the cable.

The $\varepsilon-N$ fatigue curve considering the effect of both elastic and plastic strain can be expressed by the Coffin-Manson relationship [21]:

$$
\varepsilon\left(N_{\text {cycles }}\right)=\varepsilon_{e}\left(N_{\text {cycles }}\right)+\varepsilon_{p}\left(N_{\text {cycles }}\right)==C_{1} \cdot N_{\text {cycles }}^{-\beta_{1}}+C_{2} \cdot N_{\text {cycles }}^{-\beta_{2}}
$$

where $\varepsilon\left(N_{\text {cycles }}\right)$ are the strain amplitudes leading to failure at $N_{\text {cycles }}$ number of cycles, and $C_{i}$ and $\beta_{i}$ (with $i=1$ or 2) are appropriate material constants, provided by Thies et al. (2011) [23], for a typical FOWT umbilical cable as $C_{1}=0.7692, \beta_{1}=0.5879, C_{2}=0.0219$ and $\beta_{2}=0.1745$. This curve is shown in Figure 2 , and it is the same that is used in the present paper for the fatigue analyses.

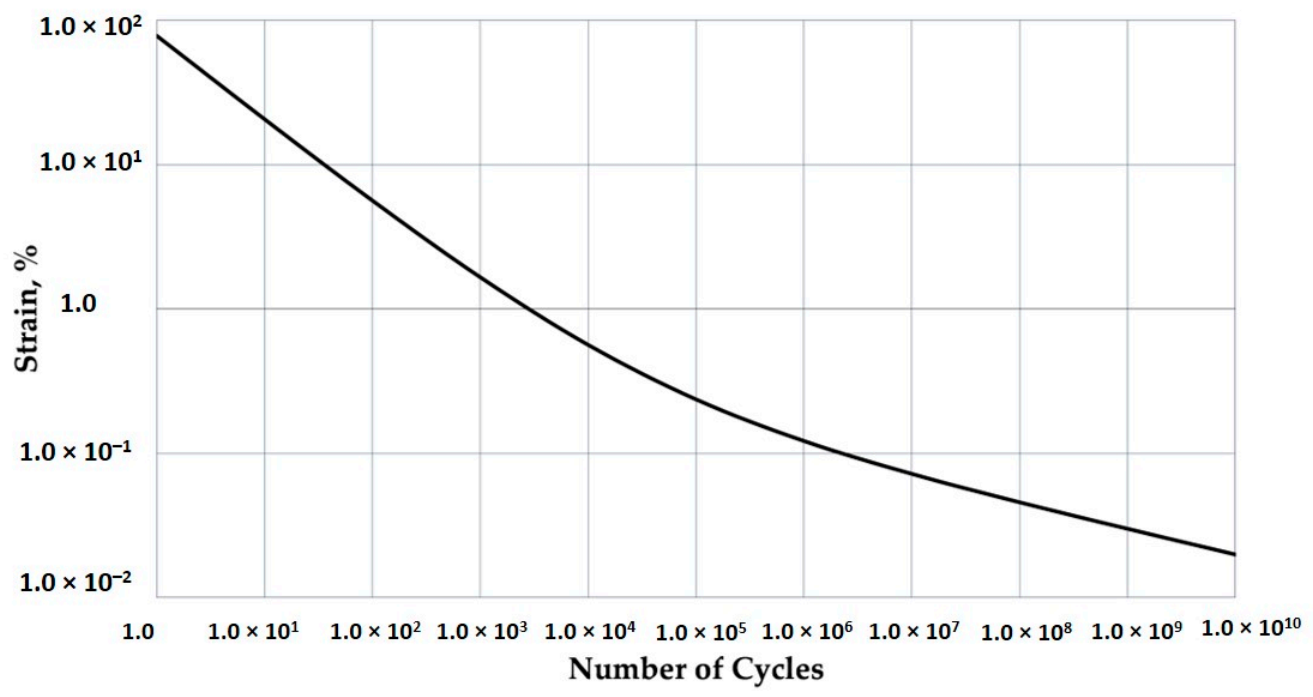

Figure 2. Strain cycle $(\varepsilon-N)$ fatigue curve for electrolytic tough pitch (ETP) copper. Adapted from Reference [11].

According to the above-mentioned calculations, the total strain time history in a critical cross-section of the cable has to be evaluated and then processed by cycle counting, leading to a set of amplitudes-number of cycle histograms which are compared with the fatigue curve of the cable in order to assess the fatigue damage $\mathrm{Dm}$ associated with each single time history. One of the most popular cycle counting methods is the rainflow method [24]. 
In the context of FOWTs, the fatigue damage was calculated for each considered sea state. Then, from the climate statistics of the site where the floating offshore wind farm was located, the joint probability distribution of the sea states in the reference period of the analysis $\operatorname{Tr}$ (e.g., 1 year) was estimated, and then the occurrences in $\operatorname{Tr}$ of the damage associated to each sea state could be evaluated.

\section{Case Study}

The NREL 5-MW wind turbine on the OC3-Hywind spar-buoy FOWT was chosen as a case study for the evaluation of the fatigue life of an inter-array turbine (umbilical) cable. This case study was chosen for its simplicity in design, suitability for modeling and the existence of numerical results in the literature $[25,26]$. As already stated, the case study was modeled in both FAST and ANSYS AQWA software. The structural, hydrodynamic and mooring line properties of the model are reported in Appendix A.

Figure 3 illustrates the model of the 5 MW NREL wind turbine on the OC3-Hywind spar-buoy in FAST (right) and the model with the same properties in ANSYS AQWA (left). It is worth noting that the electrical cable was modeled in ANSYS AQWA but it was not modeled in FAST; the motivations for this are given in Section 4. The tables in the appendix show the structural and hydrodynamic properties and the mooring properties of the model. The lazy wave configuration of the electrical cable is taken from Rentschler et al. [9], in which a hydrostatic optimization of the layout of the cable is carried out with a genetic algorithm, with the goal of minimizing the cable fatigue, and by chosing the position of the buoyancy elements as design variables, this results in a lower waveform position as the optimal solution, with an accumulative length of the buoyancy parts from $18 \%$ to $23 \%$ of the total cable length.

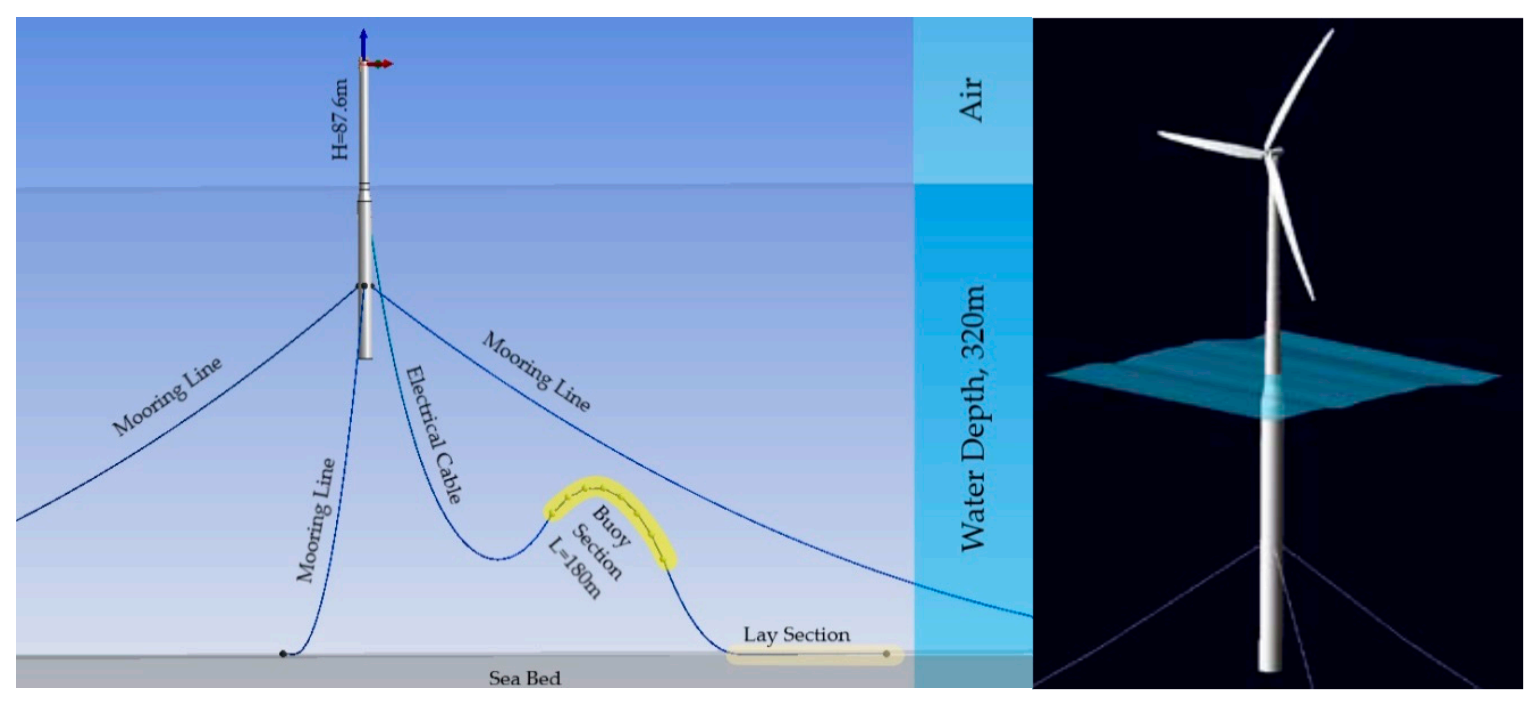

Figure 3. Left: model in ANSYS AQWA, Right: model in NREL FAST [26].

For the simulations in this paper, a typical cross-section of the electrical cable was utilized, with a single layer of galvanized steel armor wires and extruded cross-linked polyethylene (XLPE) isolators. The mechanical characteristics of the cable were assumed from the literature [6,27]. The values for the diameter, weight and strength are shown in Figure 4, with reference to Figure 1; the linear and non-linear elastic modules $E$ and $E^{\prime}$ and the yielding stress $\sigma_{y}$ were equal to $128 \mathrm{GPa}, 6.4 \mathrm{GPa}$ and $350 \mathrm{MPa}$, respectively. 


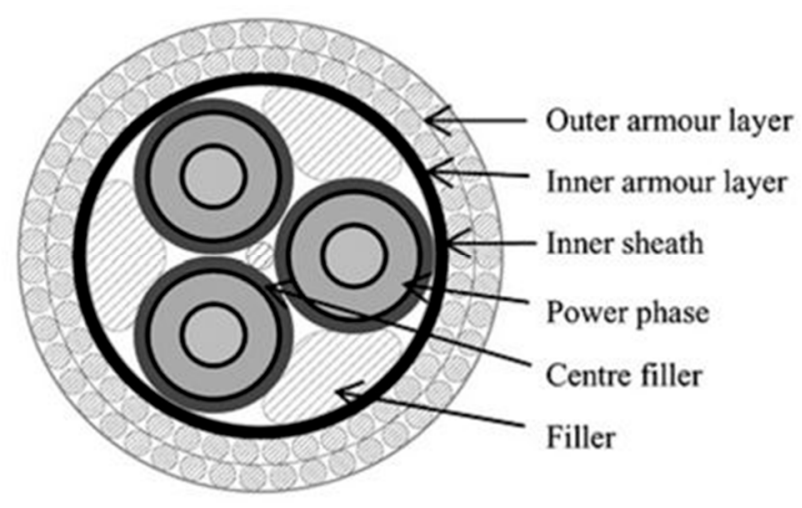

\begin{tabular}{cc}
\multicolumn{2}{c}{ Cable Specification } \\
\hline Nominal Diameter & $0.2 \mathrm{~m}$ \\
Nominal weight in seawater & $39 \mathrm{Kg}$ \\
Bending Stiffness & $10 \mathrm{kNm}$ \\
Axial stiffness & $700 \mathrm{MN}$ \\
Minimum Breaking Load & $100 \mathrm{kN}$ \\
\hline
\end{tabular}

Figure 4. Cable specifications [27].

\section{Modeling the Spar-Buoy Supported Platform and the Cable}

Depending on the wind speed and the environmental conditions, the configuration of the rotor changes: it is in the operational, rotating blade condition when the wind speed is between the cut-in and the cut-out values, while the wind turbine is parked for wind speeds higher than the cut-out value, with the blades parallel to the wind [28]. Time history analyses were conducted for $4000 \mathrm{~s}$ for different environmental conditions, and the first $400 \mathrm{~s}$ were removed in order to eliminate the transitory effects of the simulation and wait for to the model to reach the stationary operation state.

The version of the FAST Code (version 8) that was used did not allow the researchers to add extra non-structural elements (like power cables, etc.), but there were some possibilities to add extra elements in ANSYS AQWA. This was the motivation for conducting the electrical cable and the fatigue analyses in ANSYS AQWA. On the other hand, one of the issues we faced with the version of ANSYS AQWA (version 18.2) that was used was the difficulty of modeling the rotating blades in the operating conditions; consequently, the rotor-nacelle assembly was modeled there as a concentrated mass at the hub height. To mitigate this weakness, the total rotor aerodynamic load time history (force in the

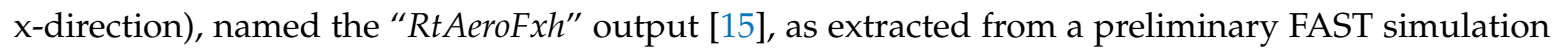
(where the electrical cable was not modeled) in a certain sea state case, was successively applied to the hub in the model in ANSYS AQWA (where the electrical cable was then modeled and meshed by 100 finite elements). Since the hydrodynamic loads were evaluated in ANSYS AQWA based on the implemented wave theory and by making use of Morrison's equation, in order to avoid the double-counting of the hydrodynamic effects during the simulation in ANSYS AQWA, the RtAeroFxh aerodynamic force was evaluated by not taking into account the three following effects: (i) presence of waves; (ii) action of sea current and; (iii) inertial effect of water volumes moving with the platform. This was because all these effects were taken into account in the subsequent ANSYS AQWA simulation.

One of the procedures that can be implemented to avoid double-counting is running the preliminary FAST analysis by fully restraining the bottom Degrees Of Freedom (DOFs) of the platform and maintaining the over-water dynamics (named the "fixed DOFs at spar" option). This procedure would completely neglect the double-counting of all the three listed effects, but, on the other hand, this option would also neglect some fluid-structure interaction (FSI) effects that have a non-negligible impact on the RtAeroFxh (e.g., the wind's incoming velocities and angles of attack are not combined with the correct translational velocities and rotational displacements experimented by the rotor during the large pitch, thrust and heave displacements of the floating platform when relative wind-rotor velocities and rotational angles are obtained for aerodynamic load calculation purposes). The second strategy for resolving the double-counting problem is to run the preliminary FAST analysis by assuming a "still water" (no sea current and no waves) and by allowing the floating platform DOFs. By adopting this strategy, the FSI effects are mostly taken into account (the relative velocities between the wind and the rotor and tower will take into account the large displacements of the floating platform induced by the wind itself); this is also important if the impact on the relative translational velocities of the 
hydrodynamic forces (less important than that of wind, which is due to both the translation and rotation of the tower) is not considered and, at the end of the process, there will also be a (partial) double-counting of the inertial effect of the water volumes moving with the platform. In this case, a compromise should be put in place to run the analysis by the joint use of the two computational codes. In order to show the differences found in the RtAeroFxh by running the preliminary analysis with three different strategies, i.e., the above-mentioned "fixed DOFs at spar" and "still water" options, and the analysis carried out by considering all the loads in FAST ("wave and current" mode, something that would cause the above-mentioned double-counting effect if the extracted RtAeroFxh is successively applied to ANSYS AQWA), the time histories of the RtAeroFxh values obtained for the three cases are compared in Figure 5 for one of the sea states considered in the following fatigue analysis: sea state 15, as identified in Table 2 by grey highlighting (wind velocity at the hub height equal to $21.7 \mathrm{~m} / \mathrm{s}$, current velocity equal to $0.5 \mathrm{~m} / \mathrm{s}$, wave height equal to $4.5 \mathrm{~m}$ with period of $10 \mathrm{~s}$ ).

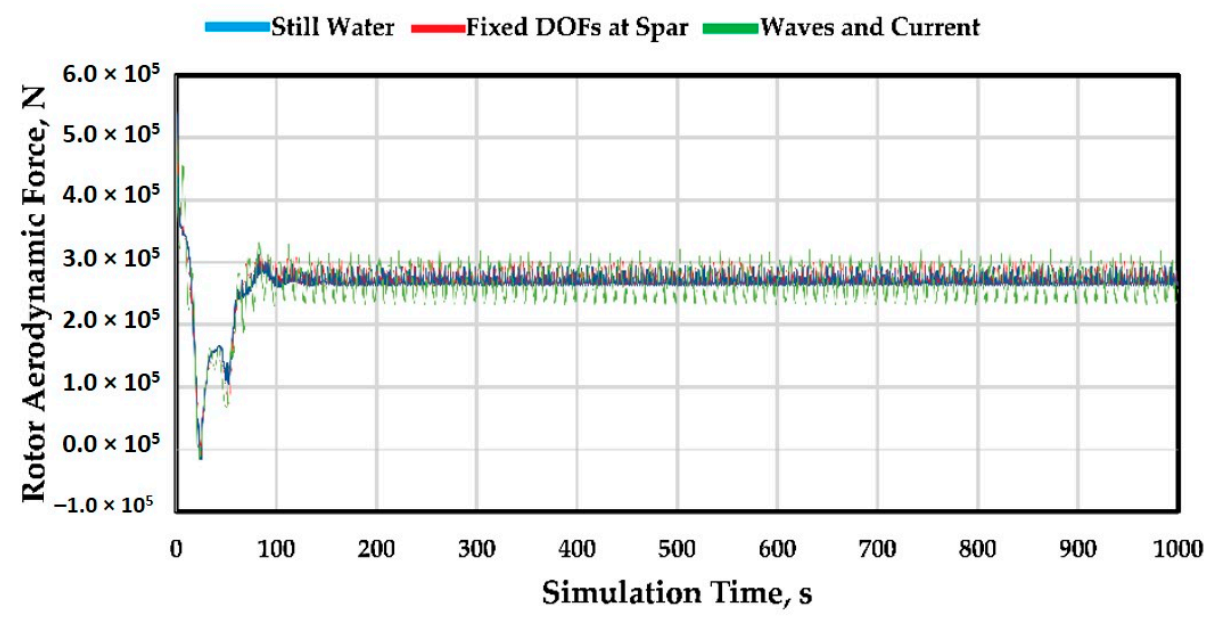

(a)

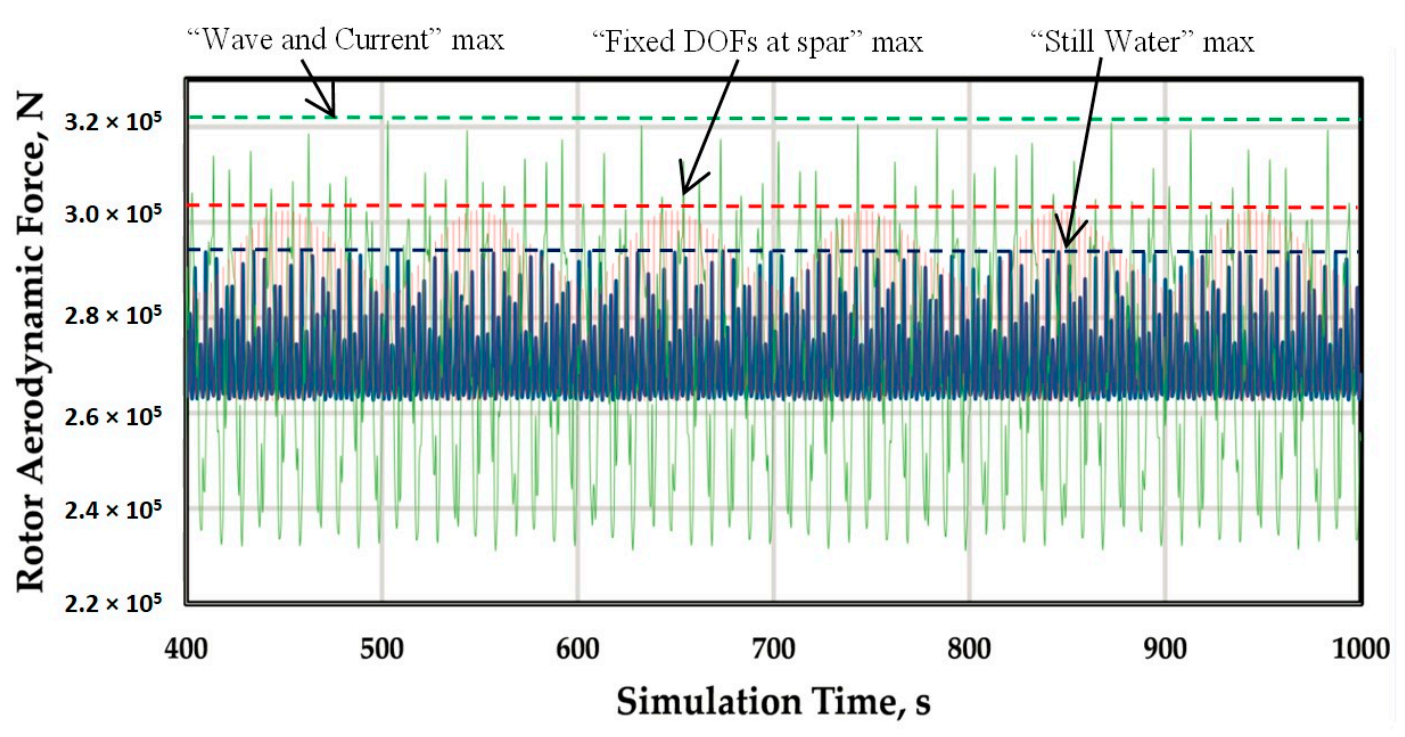

(b)

Figure 5. Cont. 


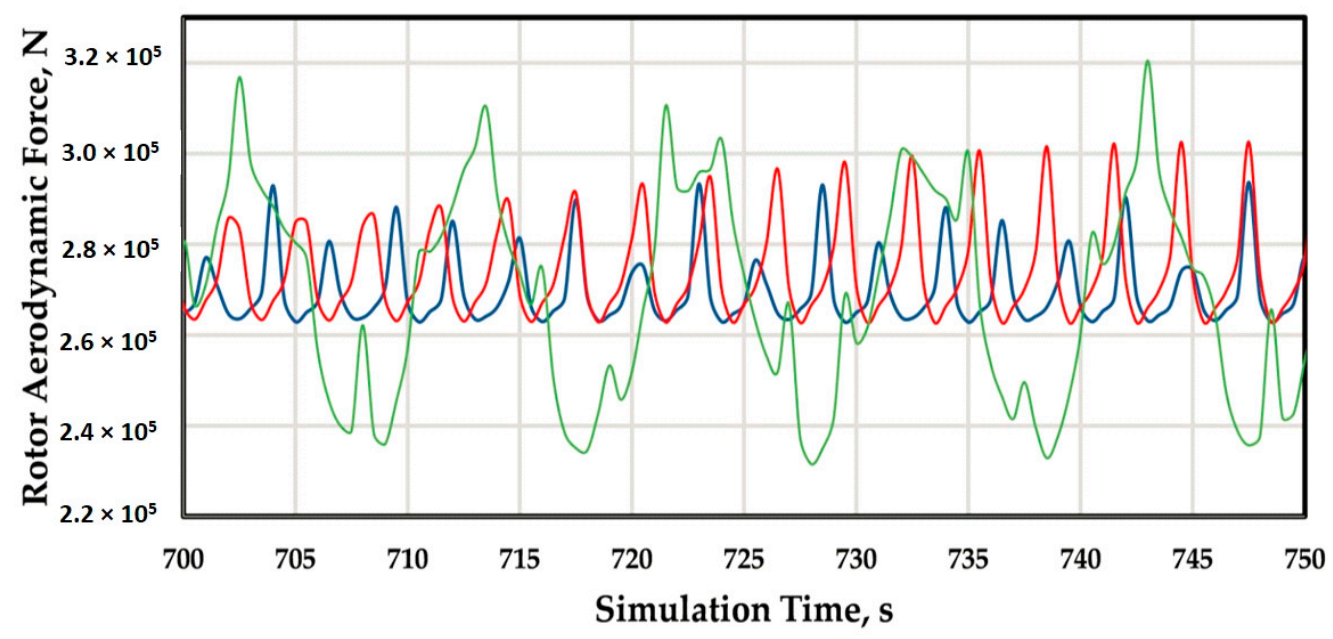

(c)

Figure 5. Rotor aerodynamic force RtAeroFx as extracted from FAST for sea state 15 and the three strategies that would be adopted for neglecting the double-counting of the hydrodynamic effects. 0-100 sec scale (a); 400-1000 sec scale (b); 700-750 sec time interval (c).

From Figure 5b, it is clear that the "fixed DOFs at spar" option provides conservative results with respect to the "still water" option, while it is also obvious that the inclusion of the waves and current would produce an additional contribution (the one that, if included, would be double counted in ANSYS AQWA) that is relevant for the examined load case. In Figure $5 c$, it is shown that the frequency content slightly changed between the three options (with different frequency contents for the "wave and current" case compared to the other two). Based on this analysis, the final choice was made to opt for the "fixed DOFs at spar" strategy in the subsequent fatigue calculations as this is on the conservative side with respect to the "still water" model.

In order to further discuss the adopted strategy in coupling the two codes, it is worthwhile to say that a step-by-step "two-way" coupling, that is, the continuous data exchange between the two codes in order to take into account the interactions of the sub-domains (e.g., aerodynamics-hydrodynamics) which are evaluated in the two different numerical codes, would be able to solve the above-mentioned problems regarding the double-counting or the neglect of some effects. When, as in this paper, some "one-way" coupling is put in place, the two codes elaborate separately the sub-domains of the problem, and for just one of them the elaboration takes into account the data coming from the other domain/code (in this paper, for example, we lost the effect of the ANSYS AQWA results on the FAST evaluations). Therefore, the use of the one-way coupling implies the acceptance of a compromise regarding the effects we lost and the accuracy of the obtained results. The correct strategy to pursue the one-way coupling is to adapt/calibrate the separate sub-domain models in a way that minimizes the aspects we lost but, more importantly, keeps the design/analysis on the conservative side. In our case, we adapted the FAST model, used for the aerodynamic sub-domain evaluation, with the main goal of being on the conservative side but with the secondary goal of not being too conservative (and far from accuracy) by trying to eliminate the double-counting of the displacements induced by the hydrodynamic forces.

\section{Model Verification}

Due to the above-mentioned joint use of the two codes, this procedure needs to be validated, especially regarding the evaluation of the hydrodynamic loads which are obtained by the two codes: having the same response of the model under hydrodynamic loads is a primary condition in order to assume that the obtained results are reliable and that the above-mentioned procedure of extracting the aerodynamic loads from FAST leads to a consistent dynamics of the system. With this purpose, a set of 
validation analyses (comparison of the platform dynamics obtained by FAST and ANSYS AQWA and comparison with the results in the literature for the same problem under different load conditions) are carried out, based on the published results of Phase IV of the NREL 5 MW FOWT [26]. Fully non-linear analyses in ANSYS AQWA and FAST are performed with all wind turbine DOFs (surge, sway, heave, pitch, roll, yaw). The environmental conditions for the validation simulation are shown in Table 1. The hydrodynamic, structural and mooring line properties were considered the same as in [26], while the electrical cable was not modeled in this validation phase.

Table 1. Environmental conditions used for model verification purposes [26].

\begin{tabular}{cc}
\hline Enabled DOFs & Platform, Tower \\
\hline Wind Condition & None \\
Wave Condition & Regular Airy: $H=6$ m and $T=10 \mathrm{~s}$ \\
Analysis Type & Time-series solution \\
\hline
\end{tabular}

Figure 6 shows the time histories of the platform surge, heave and pitch displacement considering the load case which is shown in Table 1 as obtained in the present study by ANSYS AQWA and FAST, compared with the results published in [26] as obtained with FAST ("OC3" in the figure) for validation purposes. The simulation shows there is a good agreement between the results of FAST and ANSYS AQWA.

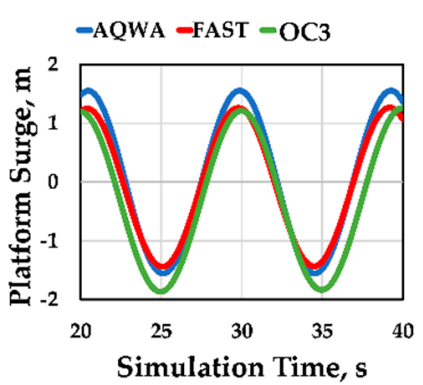

(a)

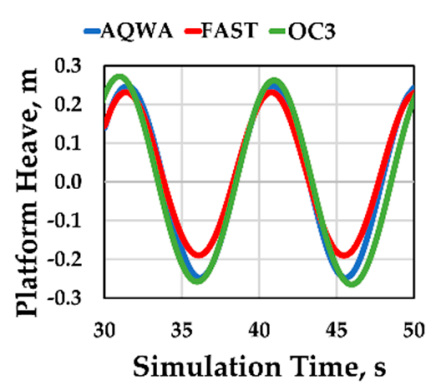

(b)

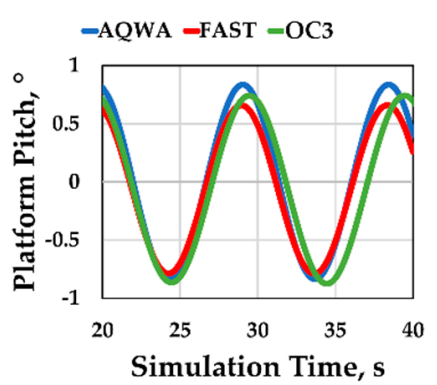

(c)

Figure 6. Comparison of the time histories of the platform main DOFs under the load case shown in Table 1, as obtained by FAST and ANSYS AQWA models. Surge (a), heave (b), pitch (c).

In the fatigue analysis presented in the next section, the motion responses of the spar-buoy platform were calculated in ANSYS AQWA under the combination of wind, current and wave loads. Concerning the wind, in each analysis, in addition to the time history of the total force acting on the rotor RtAeroFxh as extracted from FAST, the mean wind (Equation (6) below) is applied to the tower above the sea. The Airy theory for regular waves [26] is applied for the waves' dynamics computation, while Morrison's equations [26] are applied for the hydrodynamic forces evaluation. To model the environmental condition, regular sea states are assumed.

\section{Fatigue Analysis}

The above-mentioned general procedure for fatigue life evaluation has been applied to the case study by using the validated numerical models described above. The complete flowchart of the fatigue analysis procedure adopted in this study is shown in Figure 7. The goal was to determine the fatigue life in the cross-section of the cable that is located at a critical position, along with the cable development for fatigue. 


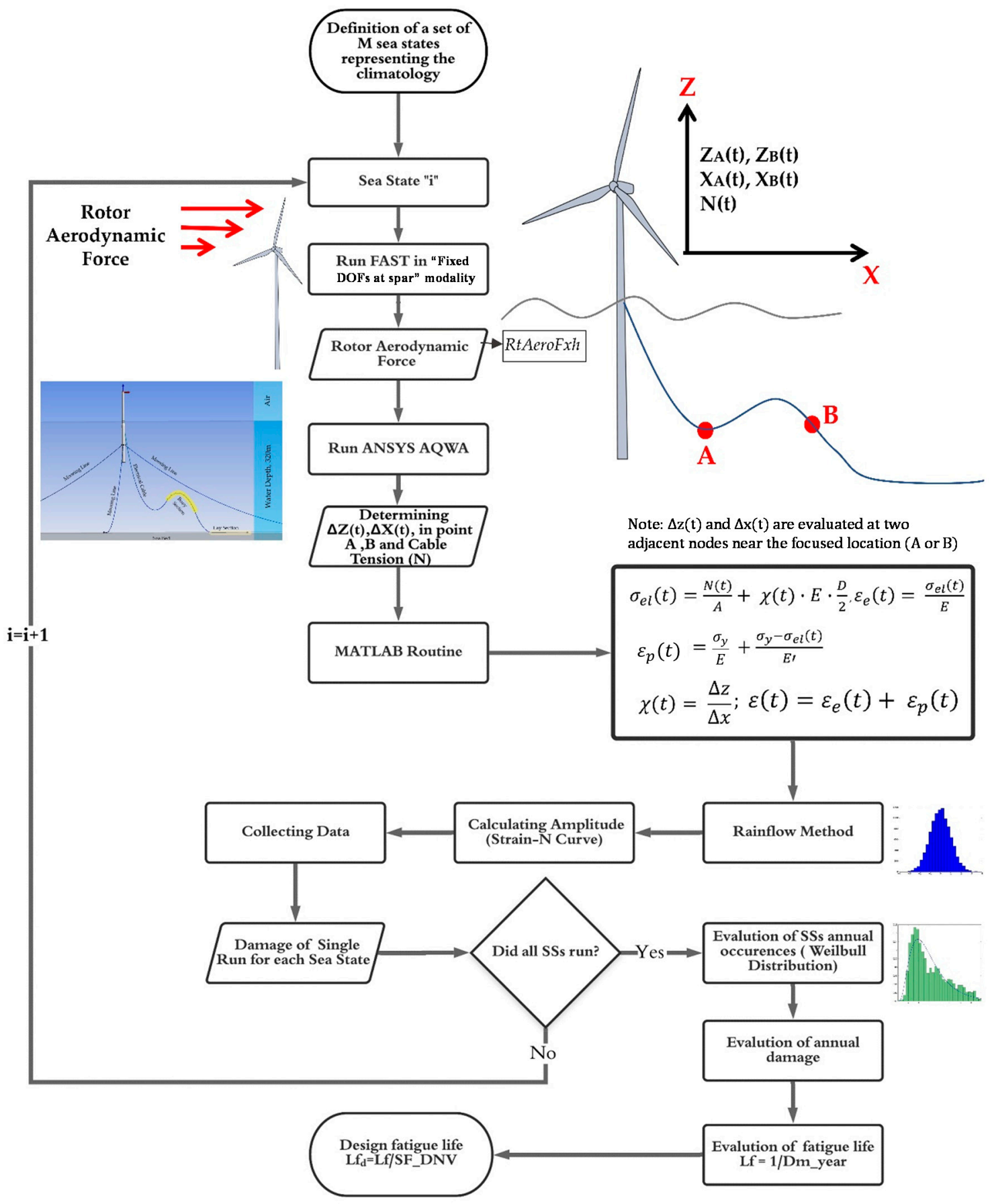

Figure 7. Fatigue analysis of dynamic electrical cable.

As already stated, for each considered loading condition (sea state "SS" in what follows), the aerodynamic forces' time histories are extracted from FAST (in "fixed DOFs at spar" conditions and without modeling the electrical cable) and applied to the top of the tower in the ANSYS AQWA model. Then, the structural response is evaluated in ANSYS AQWA by a fully non-linear time-domain analysis, considering also the model provided by the electrical cable. The outputs that are relevant for fatigue damage assessment in the electrical cable with the method described in the previous section (axial force and bending curvature in the cross-section of the cable at the location which is relevant for fatigue) are then extracted to feed an in-house developed MATLAB routine which implements the evaluation of the total strain time history as described in Equations (2)-(4). The bending curvature of the cable is obtained step-by-step as a spatial first derivative of the bending deflection, starting from the time 
histories of the displacements of the two nodes adjacent to the focused location. When the time history of the total strain in the given location for a certain SS is obtained, a MATLAB routine for the rainflow cycle counting method [24] is applied and the fatigue damage for the considered SS is evaluated at the focused location by the comparison of the cycle-counting histogram with the $\varepsilon-N$ fatigue curve shown in Figure 2. The procedure is repeated for all the relevant SSs (for a total of 20 SSs reported in Table 2). Finally, the damages obtained are multiplied by their pertinent annual occurrences, evaluated by a fitted Weibull distribution indicating the climate of the FOWT location. The total annual fatigue damage Dm_year is then evaluated as the sum of the annual fatigue damages induced by the single SSs, and the fatigue life of the cable $L f$ is evaluated as the inverse of the annual fatigue damage, while the design fatigue life $L f_{-} d$ is obtained by considering a safety factor SF_DNV equal to 10 as indicated in DNV standards [29].

Table 2. Short-term sea atates (in grey, we show the sea state used for comparison in Figure 5) [30].

\begin{tabular}{ccccccc}
\hline $\mathbf{S S}$ & $\boldsymbol{U}_{\mathbf{1 0}}(\mathbf{m} / \mathbf{s})$ & $\boldsymbol{U}(\boldsymbol{H})(\mathbf{m} / \mathbf{s})$ & $H_{\boldsymbol{s}}(\mathbf{m})$ & $\boldsymbol{T}(\mathbf{s})$ & $\boldsymbol{C v}(\mathbf{m} / \mathbf{s})$ & $\boldsymbol{P ( \% )}$ \\
\hline 1 & 5.6 & 7.279722555 & 0.675 & 4 & 0.168 & 2.24096 \\
2 & 6 & 7.799702738 & 0.675 & 5 & 0.180 & 8.68372 \\
3 & 7 & 9.099653194 & 1.050 & 4 & 0.210 & 1.96084 \\
4 & 7.80 & 10.13961356 & 1.050 & 6 & 0.234 & 14.006 \\
5 & 8.5 & 11.04957888 & 1.550 & 4 & 0.255 & 1.4006 \\
6 & 9 & 11.69955411 & 1.550 & 5 & 0.270 & 10.36444 \\
7 & 9.40 & 12.21953429 & 1.550 & 7 & 0.282 & 20.16864 \\
8 & 10.8 & 14.03946493 & 2.175 & 5 & 0.324 & 5.32228 \\
9 & 11.2 & 14.55944511 & 2.175 & 7 & 0.336 & 15.4066 \\
10 & 12 & 15.59940548 & 2.875 & 6 & 0.360 & 8.96384 \\
11 & 13.2 & 17.15934602 & 3.625 & 6 & 0.396 & 3.08132 \\
12 & 14.5 & 18.84928162 & 4.000 & 6 & 0.432 & 0.56024 \\
13 & 15.0 & 19.49925684 & 4.500 & 7 & 0.450 & 3.64156 \\
14 & 16.1 & 20.92920235 & 5.000 & 7 & 0.483 & 0.84036 \\
15 & 16.7 & 21.70917262 & 4.500 & 10 & 0.501 & 0.84036 \\
16 & 17.2 & 22.35914785 & 4.500 & 11 & 0.516 & 0.28012 \\
17 & 17.4 & 22.61913794 & 5.500 & 10 & 0.522 & 0.56024 \\
18 & 18 & 23.39910821 & 5.500 & 11 & 0.540 & 0.56024 \\
19 & 19.1 & 24.82905372 & 6.750 & 10 & 0.573 & 0.84020 \\
20 & 20 & 25.99900913 & 3.625 & 12 & 0.600 & 0.280 \\
\hline
\end{tabular}

Figure 8 shows the electrical cable configuration. As already stated, the electrical cable configuration provided in [9] was used in the simulations. The cable hung from a fixed point on the spar-buoy platform at the sea surface, and the electrical cable was modeled by 100 elements. The fatigue of the cable was calculated at different locations along the cable to individuate the most critical cross-section for fatigue. The fatigue damage was highly influenced by the position of the cross-section along the cable. For demonstration purposes, in the following, the fatigue life was evaluated for locations $\mathrm{A}$ and B along the cable, as shown in Figure 8. 


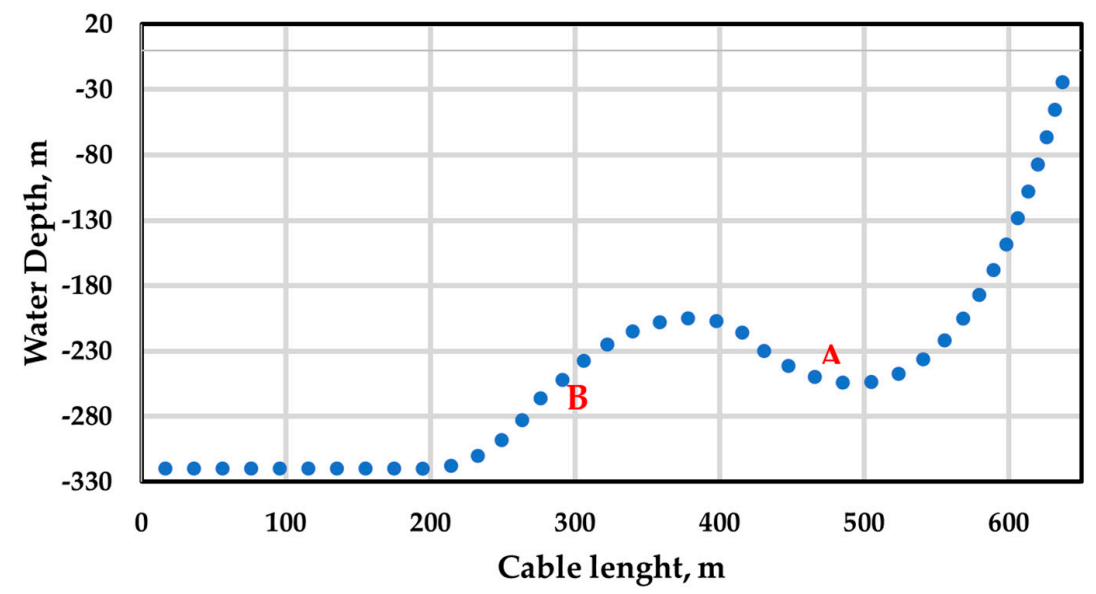

Figure 8. Electrical cable layout.

\subsection{Environmental Conditions and Considered SSs}

The SS conditions for fatigue life evaluations are selected from the South China Sea S4 area, the angle of incidence of wind and waves is fixed to the direction coinciding with to the X-axis, that is orthogonal to the cable longitudinal extension, since this is recognized to be the most critical configuration for fatigue in umbilical cables. The chosen sea states are listed in Table 2 in accordance with the wave scatter diagram of the South China Sea S4 [30] in a one year period. The wind speed profile, representing the variation of the mean wind with the height above the still water level $U(z)$, is evaluated by the power-law model shown in Equation (6), where $U_{10}$ is 10 min average wind speed at a $10 \mathrm{~m}$ height above the sea still water level, and $\alpha$ is the power-law profile [29]:

$$
U(z)=U_{10} \cdot\left(\frac{z}{10}\right)^{\alpha}
$$

Additionally, in Table 2, Hs is the wave height and $T$ is the wave period, $C v$ is the current velocity, and $P$ is the annual probability of each sea state as evaluated by a Weibull probability distribution function, which is adopted in fitting with the number of occurrences of the sea states. Equation (7) describes the Weibull probability density function, while Figure 9 shows the Weibull probability distribution function.

$$
P D F_{\text {weibull }}=\frac{\beta}{V}\left(\frac{U_{10}}{\gamma}\right)^{\beta} e^{-\left(\frac{U_{10}}{\gamma}\right)^{\beta}}
$$

where, in this paper, $\beta=2.49$ and $\gamma=10.4 \mathrm{~m} / \mathrm{s}$ are the values assumed for the shape parameter and scale parameter [31] in order to fit the available SS data.

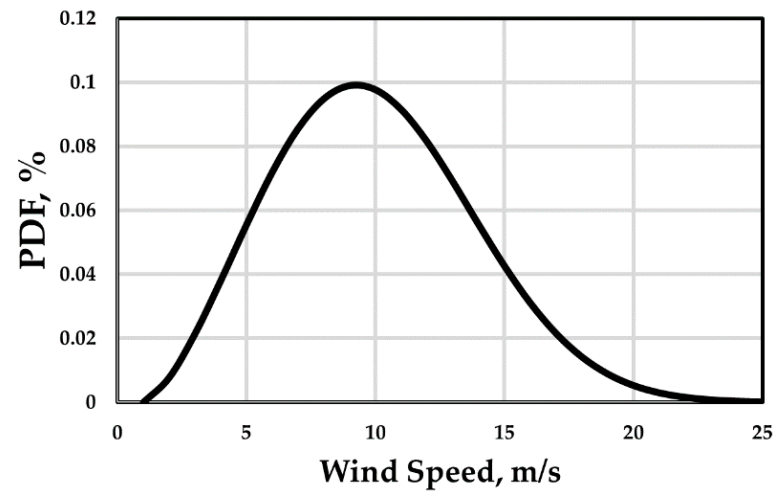

Figure 9. Weibull distribution adopted for $U_{10}$. 
Wind turbines are typically designed for 20-25 years [32]. Under average wind conditions, an onshore wind turbine can produce electricity for $4000-7000 \mathrm{~h}$ a year, corresponding to $70 \%-80 \%$ of the total hours in the year [33]. On the above basis, an average number of 15 windy hours each day for a total of 365 days during the year ( $5475 \mathrm{~h}$ per year) is considered in evaluating the occurrence of the SSs.

\subsection{Fatigue Life Estimation}

As already stated, in order to avoid the transitory effects of the simulation in the rainflow method calculations, the first $400 \mathrm{~s}$ are removed from the ANSYS AWQWA analysis output before feeding them into the cycle-counting MATLAB routine. As an example, Figure 10 shows the time histories of the cable's axial force as obtained at location A from the SS 10 simulation in Table 2. The results obtained for the annual fatigue damage at location A for the 20 SSs are shown in Figure 11, while Figure 12 shows the percentage of the contribution of each SS to the annual fatigue damage. As stated above, the annual fatigue damage due to a particular SS is evaluated by multiplying the fatigue damage obtained by the non-linear time history analysis conducted in ANSYS AQWA by the number of annual occurrences of that SS.

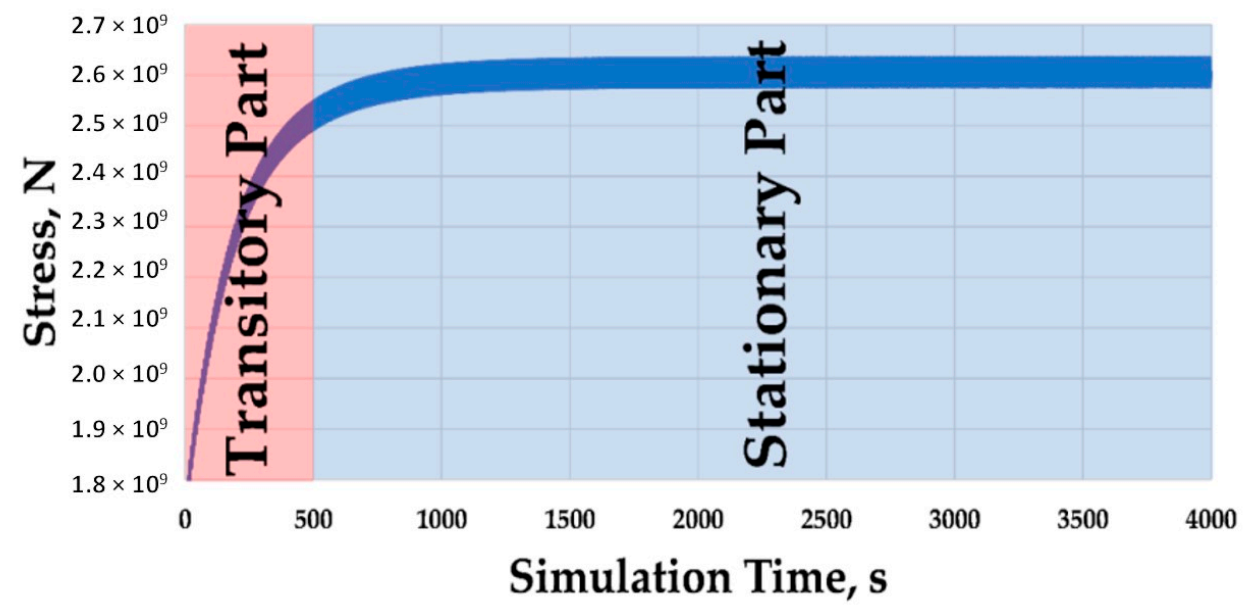

(a)

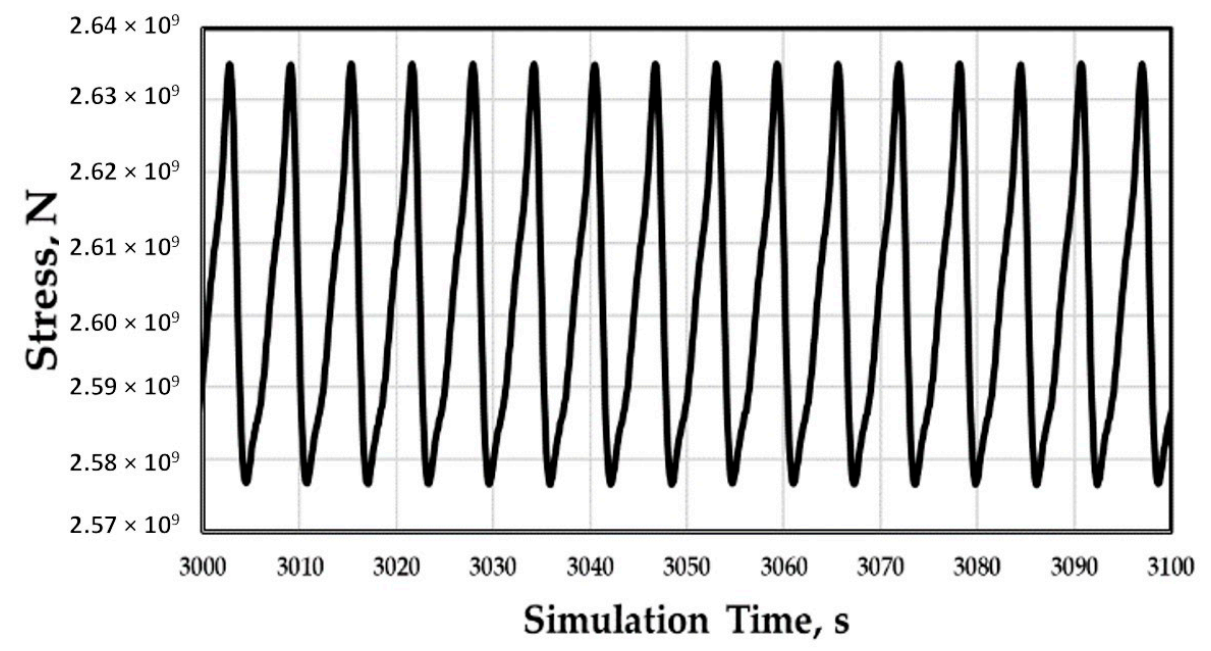

(b)

Figure 10. Example of axial stress time history in the cable at location A and for SS (sea state) 10. Whole (a); focus (b). 


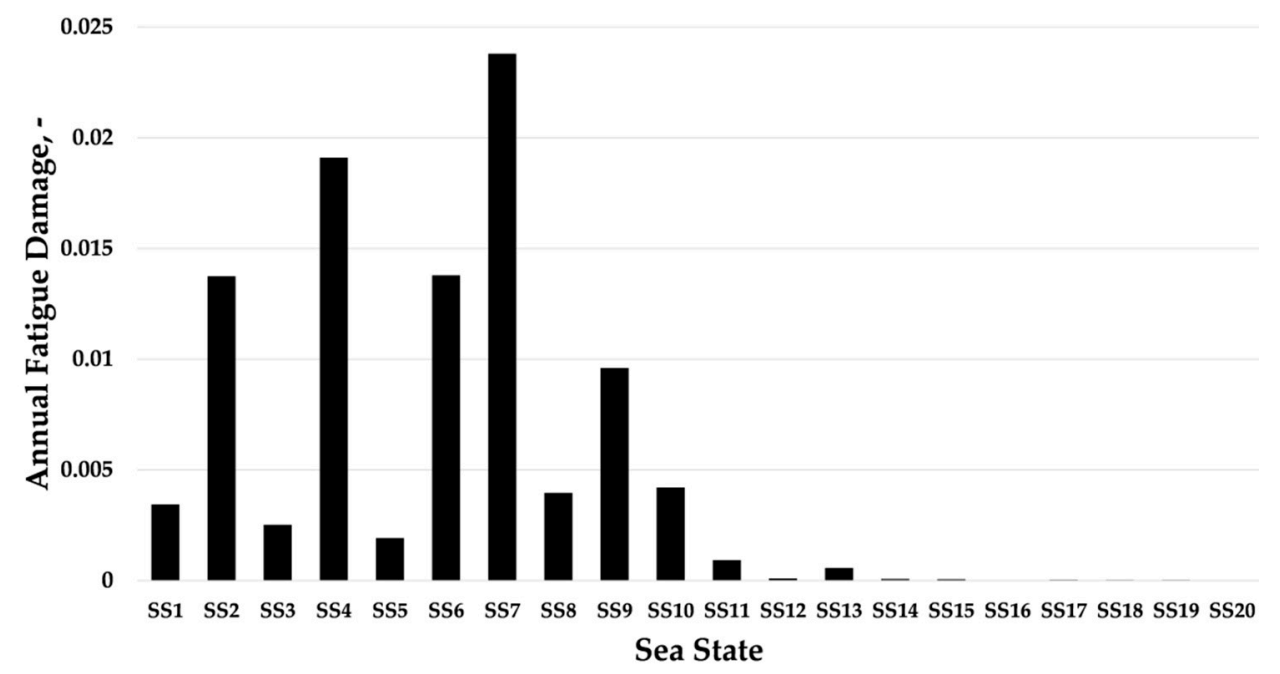

Figure 11. Annual fatigue damage induced at location A for all considered SSs.

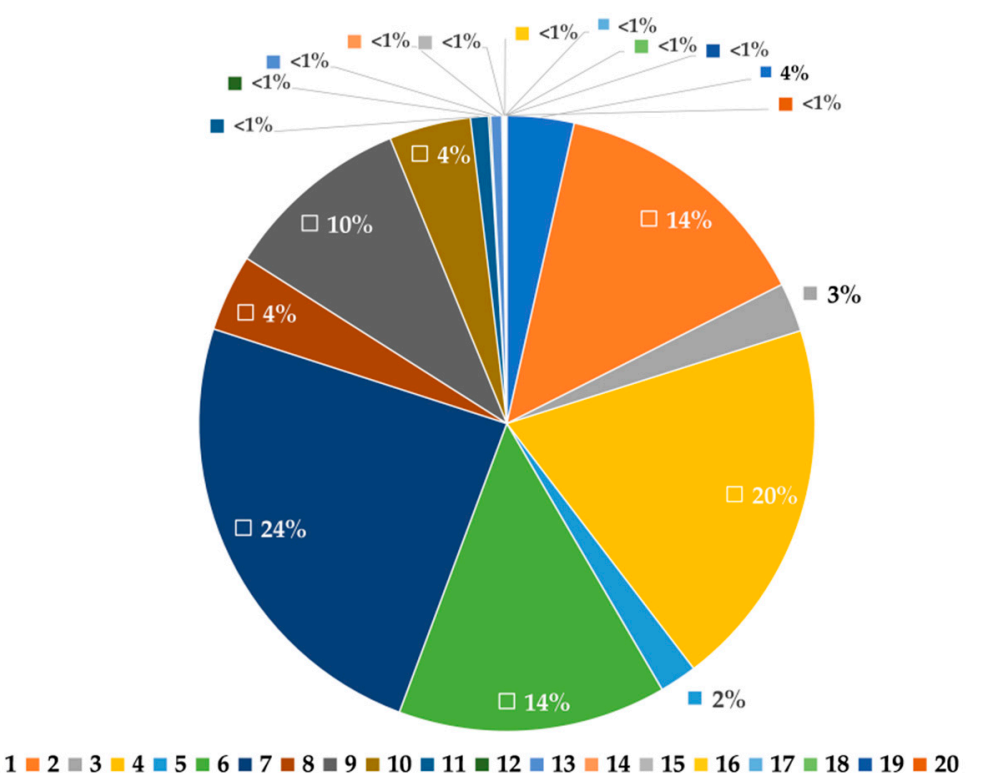

Figure 12. Relative contribution at location A to the annual fatigue damage of all considered SSs.

Finally, Table 3 represents the evaluation of the annual fatigue damage Dm_year due to all 20 of the SSs considered with their occurrences, obtained as the sum of the annual fatigue damages obtained for all SSs. From these results, it is evident that location A is critical for fatigue and that it suffers important damage which quantifies the fatigue life $L f$ of the umbilical cable to about 10 years, if scaled by the safety factor SF_DNV which is reduced to 1 year. This result confirms the notion that fatigue in electrical cables is a weak point for this kind of structure. 
Table 3. Annual fatigue damage and fatigue life estimation.

\begin{tabular}{ccc}
\hline Sea State & $\begin{array}{c}\text { Annual Fatigue Damage. } \\
\text { Location A }\end{array}$ & $\begin{array}{c}\text { Annual Fatigue Damage. } \\
\text { Location B }\end{array}$ \\
\hline 1 & $3.442737 \times 10^{-3}$ & $2.68358 \times 10^{-4}$ \\
2 & $1.3747238 \times 10^{-2}$ & $9.76374 \times 10^{-4}$ \\
3 & $2.526371 \times 10^{-3}$ & $2.0901 \times 10^{-4}$ \\
4 & $1.9108678 \times 10^{-2}$ & $1.10222 \times 10^{-3}$ \\
5 & $1.923422 \times 10^{-3}$ & $1.13001 \times 10^{-4}$ \\
6 & $1.37916 \times 10^{-2}$ & $8.4595 \times 10^{-4}$ \\
7 & $2.380188 \times 10^{-2}$ & $1.44312 \times 10^{-3}$ \\
8 & $3.962855 \times 10^{-3}$ & $2.18672 \times 10^{-4}$ \\
9 & $9.60747 \times 10^{-3}$ & $3.96218 \times 10^{-4}$ \\
10 & $4.204048 \times 10^{-3}$ & $1.88023 \times 10^{-4}$ \\
11 & $9.2328 \times 10^{-4}$ & $3.25774 \times 10^{-5}$ \\
12 & $1.00209 \times 10^{-4}$ & $3.50426 \times 10^{-6}$ \\
13 & $5.72823 \times 10^{-4}$ & $1.28245 \times 10^{-5}$ \\
14 & $8.0497 \times 10^{-5}$ & $1.65752 \times 10^{-6}$ \\
15 & $6.27443 \times 10^{-5}$ & $1.28641 \times 10^{-6}$ \\
16 & $1.97191 \times 10^{-5}$ & $3.1258 \times 10^{-7}$ \\
17 & $3.50939 \times 10^{-5}$ & $5.99213 \times 10^{-7}$ \\
18 & $2.66189 \times 10^{-5}$ & $5.45779 \times 10^{-7}$ \\
19 & $2.54863 \times 10^{-5}$ & $9.23608 \times 10^{-7}$ \\
20 & $5.53736 \times 10^{-6}$ & $4.84702 \times 10^{-7}$ \\
\hline Fatigue design life of the cable $L f_{d}$ (with the & $9.796831 \times 10^{-2}$ & $5.81566 \times 10^{-3}$ \\
Fatigue life of the cable $L f$ (years) & 10.2074 & 171.9495 \\
\hline DNV safety factor (years) & 1.02074 & 17.19495 \\
\hline
\end{tabular}

From Table 3, it is also evident that the evaluated fatigue damage is strongly dependent on the location along the cable: location B experiences much less damage (more than 10 times lower) than location A.This difference in the fatigue damage is due to the fact that the experimented oscillations and bending deformations of the cable decrease from A to B due to the presence of the buoy section of the cable development, the cable being stabilized by the buoyancy (see Figure 3).

Fatigue life assessment is highly dependent on the cable diameter and the location of the calculation point for the fatigue analysis. As already mentioned above, two different points are used in the fatigue analysis in this research in order to calculate the strain amplitude of the points (Figure 8). The suggested safety factor (SF) of 10, based on recommendations [29], is applied in the present study to assess the fatigue life.

\section{Conclusions}

This paper has assessed the fatigue life expected for an umbilical cable that is subjected to the loading regime of a typical marine environment, and under the non-linear dynamic conditions as they can be expected in a spar-buoy floating offshore wind turbine.

The main novelty of the paper lies in bringing together the mostly available knowledge to provide a comprehensive procedure/tool for the fatigue analysis of the vulnerable electrical cables of FOWTs. Such a tool cannot avoid complex structural dynamics analyses by putting in place simplistic assumptions about loads, their occurrences and numerical models. In fact, in this paper, the fatigue life of the cable's copper conductor was estimated for the FOWT site by setting out an ad-hoc complete procedure that: (i) computes the total strain time histories in the cable cross-section by the avail of fully non-linear time histories and numerical analyses of the whole turbine system including the electrical cable; (ii) evaluates the fatigue damage induced by a number of different sea states and by covering the wide range of climate and operating conditions of the turbine; (iii) defines annual occurrences of the different considered sea states for annual damage evaluation purposes based on the sea state statistics. 
Numerical analyses have been conducted by the joint use of two well-established numerical codes for offshore floating structures, which is important for allowing multi-physic and multi-scale analyses of such a complex structural system: critical points arising from this coupling have been pointed out (e.g., correct consideration of the FSI and large displacements) and the associated analytical steps/choices for ensuring that the design remains on the conservative side under the current integration level of the two codes have been discussed, which is also a point of novelty for the paper.

Regarding the fatigue design of FOWT electrical cables, our general engineering findings are:

- floating offshore wind turbine power cables must withstand a dynamic loading regime when they are attached to the support platform (e.g., spar-buoy) and are susceptible to fatigue failures. The fatigue life of the examined case is 10 years if not scaled with the safety factor prescribed by the DNV standards. When a value of 10 is applied as a safety factor, the design fatigue life reduces to 1 year only;

- the correct evaluation of all the operating (parked versus rotating blades) and climate conditions (different sea states with their occurrences) is fundamental to obtain reliable estimations of the annual fatigue damage. This is evidenced by the large difference obtained by the damage evaluated by different conditions;

- due to the concurrent contribution of both bending and axial strains, and both elastic and plastic strains to the total strains used for damage evaluation, the fatigue damage evaluated for the cable is strongly dependent on the location along the cable development where the analysis is focused, which means that evaluating the fatigue damage in different locations along the cable is crucial for the analysis.

All the above general considerations suggest that the development of reliable advanced tools for fatigue damage calculation, like the one presented in this paper, which can include non-linearities of the structural behaviours, statistics of the climatology at the site, complex dynamic behaviours of rotating blades and aero-hydrodynamics under large displacements, is an important topic for the reliable evaluation of the fatigue of electrical cables, something that is a design weakness in floating offshore wind turbine systems.

Further developments for the research are under development and include:

- consideration of the effects of irregular sea states;

- refinement of the wind action and the fluid-structure interaction model by a two way-coupling between the two codes used for the analysis, with the inclusion of aerodynamic damping;

- refinement of the electrical cable modeling (currently modeled as an equivalent homogeneous element);

- exploration of more complex dynamic configuration of the electrical cable (modeling of more than one turbine, different cable layouts).

Author Contributions: Conceptualization, M.K., F.P.; methodology, M.K., F.P. and F.B.; software, M.S. and F.P.; formal analysis, M.S.; writing-original draft preparation, M.S.; writing-review and editing, M.K. and F.P.; supervision, F.B. All authors have read and agreed to the published version of the manuscript.

Funding: This research was funded by Sapienza University of Rome, "Fondi di avvio alla Ricerca", grant number AR118164360855CD.

Conflicts of Interest: The authors declare no conflict of interest. 


\section{Appendix A}

Table A1. Structural properties of the model [25].

\begin{tabular}{cc}
\hline Description & Unit \\
\hline Gravitational acceleration $\left(\mathrm{m} / \mathrm{s}^{2}\right)$ & 9.80665 \\
Hub mass $(\mathrm{kg})$ & 56780 \\
Hub inertia about rotor axis [3 blades] or teeter axis [2 blades] $\left(\mathrm{kg} \mathrm{m}^{2}\right)$ & 115926 \\
Generator inertia about HSS $\left(\mathrm{kg} \mathrm{m}^{2}\right)$ & 534.116 \\
Nacelle mass $(\mathrm{kg})$ & 240000 \\
Nacelle inertia about yaw axis $\left(\mathrm{kg} \mathrm{m}^{2}\right)$ & $60789.2 \times 10^{6}$ \\
Yaw bearing mass $(\mathrm{kg})$ & 0 \\
Platform mass $(\mathrm{kg})$ & $7.46633 \times 10^{6}$ \\
Platform inertia for roll tilt rotation about the platform CM $\left(\mathrm{kg} \mathrm{m}^{2}\right)$ & $4.22923 \times 10^{9}$ \\
Platform inertia for pitch tilt rotation about the platform CM $\left(\mathrm{kg} \mathrm{m}^{2}\right)$ & $4.22923 \times 10^{9}$ \\
Platform inertia for yaw rotation about the platform CM $\left(\mathrm{kg} \mathrm{m}^{2}\right)$ & $1.6423 \times 10^{8}$ \\
\hline
\end{tabular}

Table A2. Hydrodynamic properties of the model [25].

\begin{tabular}{cc}
\hline Description & Unit \\
Water density $\left(\mathrm{kg} / \mathrm{m}^{3}\right)$ & 1025 \\
Water depth (meters) & 320 \\
Displaced volume of water when the platform is in its undisplaced position $\left(\mathrm{m}^{3}\right)$ & 8029.21 \\
Incident wave kinematics model & Regular \\
Analysis time for incident wave calculations $(\mathrm{s})$ & 3630 \\
Time step for incident wave calculations & 0.25 \\
Significant wave height of incident waves (meters) & 6 \\
Peak-spectral period of incident waves & 10 \\
Range of wave directions(degrees) & 90 \\
Wave Type & Stokes 2 nd-order wave theory \\
Low frequency cutoff used in the summation frequencies (rad/s) & 0.1 \\
High frequency cutoff used in the summation frequencies $(\mathrm{rad} / \mathrm{s})$ & 1.9132 \\
Current profile model & No Current \\
Analysis time for wave $(\mathrm{s})$ & 2000 \\
Time step for wave $(\mathrm{s})$ & 0.0125 \\
Additional linear damping in surge N/(m/s) & 100,000 \\
Additional linear damping in sway N/(m/s) & 100,000 \\
Additional linear damping in heave N/(m/s) & 130,000 \\
Additional linear damping in yaw Nm $(\mathrm{rad} / \mathrm{s})$ & $13,000,000$ \\
Hydrostatic restoring in heave $(\mathrm{N} / \mathrm{m})$ & 332,941 \\
Hydrostatic restoring in roll $(\mathrm{Nm} / \mathrm{rad})$ & $-4,999,180,000$ \\
Hydrostatic restoring in pitch $(\mathrm{Nm} / \mathrm{rad})$ & $-4,999,180,000$ \\
\hline
\end{tabular}

Table A3. Mooring line properties of the model [25].

\begin{tabular}{cc}
\hline Description & Unit \\
\hline The mass per unit length of the line $(\mathrm{kg} / \mathrm{m})$ & 77.7066 \\
The line stiffness, product of elasticity modulus and cross-sectional area $(\mathrm{N})$ & $384.243 \times 10^{6}$ \\
Diameter $(\mathrm{m})$ & 0.09 \\
\hline
\end{tabular}

\section{References}

1. de Alegria, I.M.; Martín, J.L.; Kortabarria, I.; Andreu, J.; Ereño, P.I. Transmission alternatives for offshore electrical power. Renew. Sustain. Energy Rev. 2009, 13, 1027-1038. [CrossRef]

2. Green, J.; Bowen, A.; Fingersh, L.J.; Wan, Y.H. Electrical collection and transmission systems for offshore wind power. Offshore Technol. Conf. Proc. 2007, 4, 2215-2221.

3. Dai, T.; Sævik, S.; Ye, N. Experimental and numerical studies on dynamic stress and curvature in steel tube umbilicals. Mar. Struct. 2020, 72, 102724. [CrossRef] 
4. Yang, S.H.; Ringsberg, J.W.; Johnson, E. Parametric study of the dynamic motions and mechanical characteristics of power cables for wave energy converters. J. Mar. Sci. Technol. 2018, 23, 10-29. [CrossRef]

5. Yang, S.H.; Ringsberg, J.W.; Johnson, E.; Hu, Z. Biofouling on mooring lines and power cables used in wave energy converter systems-Analysis of fatigue life and energy performance. Appl. Ocean Res. 2017, 65, 166-177. [CrossRef]

6. Nasution, F.P.; Sævik, S.; Gjøsteen, J.K.Ø. Fatigue analysis of copper conductor for offshore wind turbines by experimental and FE method. Energy Proc. 2012, 24, 271-280. [CrossRef]

7. Watson, S.; Moro, A.; Reis, V.; Baniotopoulos, C.; Barth, S.; Bartoli, G.; Bauer, F.; Boelman, E.; Bosse, D.; Cherubini, A.; et al. Future emerging technologies in the wind power sector: A European perspective. Renew. Sustain. Energy Rev. 2019, 113, 109270. [CrossRef]

8. Lotsberg, I. Fatigue Design of Marine Structures; Cambridge University Press: Cambridge, UK, 2016.

9. Rentschler, M.U.T.; Adam, F.; Chainho, P. Design optimization of dynamic inter-array cable systems for floating offshore wind turbines. Renew. Sustain. Energy Rev. 2019, 111, 622-635. [CrossRef]

10. Deltares. Joint Industry Project Cables Lifetime Monitoring. 2018. Available online: https://www. deltares.nl/app/uploads/2018/04/PB_Joint-Industry-Project-Cables-Life-Time-Monitoring_v2.pdf (accessed on 10 June 2020).

11. Karlsen, S.; Slora, R.; Heide, K.; Lund, S.; Eggertsen, F.; Osborg, P.A. Dynamic deep water power cables. In Proceedings of the 9th International Conference and Exhibition for Oil and Gas Resources Development of the Russian Arctic and CIS Continental Shelf, RAO/CIS Offshore, St Petersburg, Russian, 15 September 2009.

12. Homb, H.R. Fatigue Analysis of Mooring Lines on the Floating Wind Turbine Hywind Demo. Master's Thesis, Norges Teknisk-Naturvitenskaplige University, Trondheim, Norway, 2013.

13. Manenti, S.; Petrini, F. Dynamic analysis of an offshore wind turbine: Wind-waves nonlinear interaction. In Proceedings of the 12th Biennial ASCE Aerospace Division International Conference (Earth \& Space 2010), Honolulu, HI, USA, 14-17 March 2010.

14. Karimirad, M. Modeling aspects of a floating wind turbine for coupled wave-wind-induced dynamic analyses. Renew. Energy 2013, 53, 299-305. [CrossRef]

15. Jonkman, J.M.; Buhl, M.L., Jr. FAST User's Guide; National Renewable Energy Laboratory: Golden, CO, USA, 2005.

16. Canonsburg, T.D. AQWA User Manual; ANSYS, Inc.: Cannon Sburg, PA, USA, 2012.

17. DNV GL. DNVGL-RP-C203: Fatigue Design of Offshore Steel Structures; DNV GL: Oslo, Norway, 2016.

18. DNV GL. DNV-OS-J101-Design of Offshore Wind Turbine Structures; DNV GL: Oslo, Norway, 2014.

19. Veritas, D.N. DNV-OS-J103: Design of Floating Wind Turbine Structures, Offshore Standard; DNV GL: Oslo, Norway, 2013.

20. Cárdenas, N.O.; Machado, I.F.; Gonçalves, E. Cyclic loading and marine environment effects on the properties of HDPE umbilical cables. J. Mater. Sci. 2007, 42, 6935-6941. [CrossRef]

21. Dieter, G.E.; Bacon, D. Mechanical Metallurgy; McGraw-Hill: New York, NY, USA, 1986; Volume 3.

22. Drexler, E.S.; Simon, N.J.; Reed, R.P. Properties of Copper and Copper Alloys at Cryogenic Temperatures. No. NIST-MN-177. NIST; National Institute of Standards and Technology (MSEL): Buolder, CO, USA, 1992.

23. Thies, P.R.; Johanning, L.; Smith, G.H. Assessing mechanical loading regimes and fatigue life of marine power cables in marine energy applications. J. Risk Reliab. 2012, 226, 18-32. [CrossRef]

24. Rychlik, I. A new definition of the rainflow cycle counting method. Int. J. Fatigue 1987, 9, 119-121. [CrossRef]

25. Jonkman, J. Definition of the Floating System for Phase IV of OC3. No. NREL/TP-500-47535; National Renewable Energy Laboratory (NREL): Golden, CO, USA, 2010.

26. Jonkman, J.; Musial, W. Offshore Code Comparison Collaboration (OC3) for IEA Task 23 Offshore Wind Technology and Deployment (NREL/TP-5000-48191); National Renewable Energy Laboratory (NREL): Golden, CO, USA, 2010.

27. Loos, B. Operability Limits Based on Vessel Motions for Submarine Power Cable Installation. Master's Thesis, Royal Boskalis Westminster NV, Papendrecht, The Netherlands, 2017.

28. Karimirad, M.; Moan, T. Stochastic dynamic response analysis of a tension leg spar-type offshore wind turbine. J. Wind Energy (Wiley) 2013, 16, 953-973. [CrossRef]

29. DNV GL. DNV-RP-F401, Electrical Power Cables in Subsea Applications; DNV GL: Oslo, Norway, 2012.

30. Qiao, D.; Yan, J.; Ou, J. Fatigue analysis of deepwater hybrid mooring line under corrosion effect. Pol. Marit. 2014, 21, 68-76. [CrossRef]

31. Chang, R.; Zhu, R.; Badger, M.; Hasager, C.B.; Xing, X.; Jiang, Y. Offshore wind resources assessment from multiple satellite data and WRF modeling over South China Sea. Remote Sens. 2015, 7, 467-487. [CrossRef] 
32. Bouty, C.; Schafhirt, S.; Ziegler, L.; Muskulus, M. Lifetime extension for large offshore wind farms: Is it enough to reassess fatigue for selected design positions? Energy Procedia 2017, 137, 523-530. [CrossRef]

33. Jensen, P.C.; Jacobsen, S.H. Wind Turbines in Denmark; Danish Energy Agency: København, Denmark, 2009.

(C) 2020 by the authors. Licensee MDPI, Basel, Switzerland. This article is an open access article distributed under the terms and conditions of the Creative Commons Attribution (CC BY) license (http://creativecommons.org/licenses/by/4.0/). 